- Original Paper •

\title{
Increased Light, Moderate, and Severe Clear-Air Turbulence in Response to Climate Change
}

\author{
Paul D. WILLIAMS* \\ Department of Meteorology, University of Reading, Reading RG6 6BB, United Kingdom
}

(Received 31 October 2016; revised 20 February 2017; accepted 28 February 2017)

\begin{abstract}
Anthropogenic climate change is expected to strengthen the vertical wind shears at aircraft cruising altitudes within the atmospheric jet streams. Such a strengthening would increase the prevalence of the shear instabilities that generate clear-air turbulence. Climate modelling studies have indicated that the amount of moderate-or-greater clear-air turbulence on transatlantic flight routes in winter will increase significantly in future as the climate changes. However, the individual responses of light, moderate, and severe clear-air turbulence have not previously been studied, despite their importance for aircraft operations. Here, we use climate model simulations to analyse the transatlantic wintertime clear-air turbulence response to climate change in five aviation-relevant turbulence strength categories. We find that the probability distributions for an ensemble of 21 clear-air turbulence diagnostics generally gain probability in their right-hand tails when the atmospheric carbon dioxide concentration is doubled. By converting the diagnostics into eddy dissipation rates, we find that the ensembleaverage airspace volume containing light clear-air turbulence increases by $59 \%$ (with an intra-ensemble range of $43 \%-68 \%$ ), light-to-moderate by $75 \%$ (39\%-96\%), moderate by $94 \%$ (37\%-118\%), moderate-to-severe by $127 \%(30 \%-170 \%)$, and severe by $149 \%(36 \%-188 \%)$. These results suggest that the prevalence of transatlantic wintertime clear-air turbulence will increase significantly in all aviation-relevant strength categories as the climate changes.
\end{abstract}

Key words: turbulence, climate change, aviation, jet stream

Citation: Williams, P. D., 2017: Increased light, moderate, and severe clear-air turbulence in response to climate change. Adv. Atmos. Sci., 34(5), 576-586, doi: 10.1007/s00376-017-6268-2.

\section{Introduction}

The climate is changing-not just where we live at ground level, but also where we fly at 30 000-40 000 feet. Climate change may have important consequences for aviation, because the meteorological characteristics of the atmosphere influence airport operations, flight routes, journey times, and the safety and comfort of passengers and crew. The contribution of aviation to climate change has long been recognised (Lee et al., 2009). In contrast, the impacts of climate change on aviation have only recently begun to emerge, as discussed by Puempel and Williams (2016) in a recent article for the International Civil Aviation Organization (ICAO). In terms of airport operations, rising sea levels and storm surges threaten coastal airports, many of which are located at altitudes of only a few metres above the mean sea level (Burbidge, 2016). Warmer air on runways is imposing increasingly frequent take-off weight restrictions (Coffel and Horton, 2015). More extreme weather, such as an increase in the frequency of lightning strikes (Romps et al., 2014), may

\footnotetext{
* Corresponding author: Paul D. WILLIAMS

Email: p.d.williams@reading.ac.uk
}

increase the probability of flight disruptions and delays. At cruising altitudes, shifting wind patterns may modify optimal flight routes and affect travel times (Karnauskas et al., 2015; Irvine et al., 2016; Williams, 2016), and stronger jet-stream wind shears may increase clear-air turbulence (Williams and Joshi, 2013, 2016).

In the field of climate science, the midlatitude jet streams in both the northern and southern hemispheres are expected to strengthen at aircraft cruising altitudes as the climate changes (Lorenz and DeWeaver, 2007; Solomon and Polvani, 2016). The strengthening of these thermal winds occurs because, despite polar amplification of warming in the lower troposphere, increased carbon dioxide $\left(\mathrm{CO}_{2}\right)$ is enhancing the column-averaged pole-to-equator temperature gradient in the midlatitudes, through the combined effect of tropospheric warming and stratospheric cooling (Shine et al., 2003; Delcambre et al., 2013; Goessling and Bathiany, 2016). The increase in the magnitude of the meridional temperature gradient at aircraft cruising altitudes stems from robust thermodynamic effects and is unlikely to be significantly abated by feedbacks from the dynamics (Vallis et al., 2015). In the lower troposphere, the result of the temperature changes is weaker zonal winds, which may cause more extreme weather 
(Francis and Vavrus, 2012). However, in the upper troposphere and lower stratosphere, the result is stronger zonal winds (Delcambre et al., 2013; Simpson, 2016).

In the field of aviation turbulence, observational studies generally support the hypothesis that clear-air turbulence is generated by the breaking of unstable Kelvin-Helmholtz waves in highly sheared regions of the atmosphere (Endlich, 1964; Atlas et al., 1970; Watkins and Browning, 1973). This hypothesis concurs with evidence that the jet stream contains about three times more clear-air turbulence than the rest of the atmosphere (Reiter, 1963, Section 9.2). The hypothesis also concurs with evidence that eastbound transatlantic flights, being closer to the strong tailwinds in the core of the jet stream, encounter more clear-air turbulence than westbound transatlantic flights (Kim et al., 2016). Gravity waves, including those generated as the atmosphere adjusts to a loss of balance (Williams et al., 2003, 2005, 2008), may play a role by initiating the Kelvin-Helmholtz instability in an otherwise stable part of the atmosphere (Knox et al., 2008; McCann et al., 2012).

It follows from the above discussion that anthropogenic climate change, by strengthening the vertical wind shears at aircraft cruising altitudes within the jet streams, may be increasing the frequency and intensity of clear-air turbulence. As reviewed by Williams and Joshi (2016), evidence is emerging of upward trends in recent turbulence statistics (FAA, 2006; Jaeger and Sprenger, 2007; Wolff and Sharman, 2008; Kim and Chun, 2011), although the interpretation of these trends requires caution in some cases. Climate change may continue to increase the prevalence of clear-air turbulence in the coming decades. Climate modelling studies have indicated that the volume of airspace containing moderateor-greater clear-air turbulence on transatlantic flight routes in winter will increase by $40 \%-170 \%$, relative to pre-industrial times, when the $\mathrm{CO}_{2}$ is doubled (Williams and Joshi, 2013).

An intensification of clear-air turbulence could have important consequences for aviation. Turbulence is hazardous to aircraft and is the underlying cause of many people's fear of air travel (Sharman et al., 2012). The median length of a patch of turbulence is currently about $60 \mathrm{~km}$, which equates to about five minutes of flying time, and the median thickness is currently about $1 \mathrm{~km}$, which limits the efficacy of altitude changes as an evasive manoeuvre (Sharman et al., 2014). Conservative estimates indicate that there are 790 turbulence encounters annually for scheduled United States carriers, resulting in 687 minor injuries to flight attendants, 38 serious injuries to flight attendants, 120 minor injuries to passengers, and 17 serious injuries to passengers (Kauffmann, 2002). However, the actual injury rates are probably much higher because of under-reporting, with other estimates indicating that there are over 63000 encounters with moderateor-greater turbulence and 5000 encounters with severe-orgreater turbulence annually (Sharman et al., 2006). In addition to injuring passengers and crew, turbulence can also cause structural damage to aircraft. For example, a plane flying over Colorado on 9 December 1992 encountered extreme clear-air turbulence, which tore off about $6 \mathrm{~m}$ of its left wing and one of its four engines (Clark et al., 2000).

The economic costs of turbulence arise from injuries to passengers and crew, damage to airframes and cabins, flight delays, inspections, repairs, and post-accident investigations. Estimates of the total economic cost vary from around US\$100 million annually (Riddaway, 1998) to nearly US\$200 million annually for United States carriers alone (Williams, 2014). The operational challenges associated with any future increase in turbulence are compounded by the projected future growth of the aviation sector. Historically, global air traffic (measured in passenger-kilometers) has experienced an average long-term growth rate of 5\% per year, which corresponds to a doubling period of about 14 years. According to Boeing's market outlook, this trend is expected to continue for at least the next 20 years (Warner, 2013).

Even present-day encounters with vertical and horizontal high-altitude wind shear may infringe current aircraft certification envelopes, according to accident and incident investigations (ICAO, 2015). New evidence indicates that only $14 \%$ of aircraft encounters with turbulence occur in the vicinity of convection (Meneguz et al., 2016). If true, this evidence suggests that the proportion of encounters that are attributable to clear-air turbulence and mountain waves is $86 \%$, which is much higher than previously thought. Pilots are known to be more likely to attempt evasive manoeuvres as the likelihood of encountering moderate-to-severe turbulence increases (Krozel et al., 2011). Therefore, in a more turbulent atmosphere, flight paths could become more convoluted, lengthening journey times and increasing fuel consumption and emissions. Turbulence causes wear-and-tear to airframes, which could require more time out of service while undergoing routine inspections and maintenance. Finally, air-to-air refuelling has been proposed as a method to reduce fuel consumption and emissions, but it requires mid-air contact between the cruiser and feeder planes, and turbulence poses a hazard to such operations (Lee, 2013).

In their study on the future response of clear-air turbulence to climate change, Williams and Joshi (2013) focused on turbulence in the moderate-or-greater strength category. This approach has two limitations. First, light and light-tomoderate turbulence are excluded from consideration. Although turbulence in these categories is not generally a safety risk to passengers or crew, it does nevertheless distress nervous passengers and cause mild wear-and-tear to airframes. The second limitation of focussing on moderate-or-greater turbulence is that moderate-to-severe and severe turbulence are included together in the same category as moderate turbulence. Unlike turbulence in the weaker categories, severe turbulence does pose a safety risk to passengers and crew, because it causes aircraft to execute random motions with vertical accelerations that exceed the gravitational acceleration (Lane et al., 2012). Therefore, severe turbulence arguably warrants separate consideration.

For the above reasons, the present paper extends the analysis of Williams and Joshi (2013), by analysing the transatlantic wintertime clear-air turbulence response to climate change in five individual aviation-relevant turbulence 
strength categories. The methodology and results are presented in Section 2. The paper concludes with a summary and discussion in Section 3.

\section{Methodology and results}

To extend the analysis of Williams and Joshi (2013), for consistency we use the same geographic area $\left(50^{\circ}-75^{\circ} \mathrm{N}\right.$, $\left.10^{\circ}-60^{\circ} \mathrm{W}\right)$ and altitude $(200 \mathrm{hPa})$. The geographic area is chosen because it lies within the North Atlantic flight corridor, which is the busiest oceanic airspace in the world. It contains the majority of transatlantic traffic, as indicated by gridded global inventories of fuel burn and emissions obtained from the Federal Aviation Administration's Aviation Environment Design Tool (Kim et al., 2005; Malwitz et al., 2005; Wilkerson et al., 2010; Wilcox et al., 2012). The altitude is chosen because it is within the range of permitted flight levels for the North Atlantic flight corridor (Irvine et al., 2013). According to a special report by the Intergovernmental Panel on Climate Change, the cruising altitudes of civil aircraft are not expected to increase significantly over the next few decades, because of physical limitations and costs (Penner et al., 1999, Section 7.2.2).

For consistency, we also use the same season (winter), climate model (GFDL-CM2.1), anthropogenic forcing simulations (pre-industrial and doubled- $\mathrm{CO}_{2}$ ), and 21-member ensemble of clear-air turbulence diagnostics as Williams and Joshi (2013). Winter is chosen because it is the season in which the prevalence of clear-air turbulence peaks in the North Atlantic sector (Jaeger and Sprenger, 2007). The climate model is chosen because the simulated upper-level winds in the northern extra-tropics agree well with reanalysis data, and because the spatial pattern of clear-air turbulence over the North Atlantic diagnosed from reanalysis data is successfully captured by the model (Williams and Joshi, 2013). The numerical resolution of the atmosphere is $2.5^{\circ}$ in longitude, $2.0^{\circ}$ in latitude, and $50 \mathrm{hPa}$ in pressure altitude around the $200 \mathrm{hPa}$ level. The doubled- $\mathrm{CO}_{2}$ simulation is chosen because $\mathrm{CO}_{2}$ is projected to reach twice its preindustrial concentration by the middle of this century, according to moderate scenarios for future emissions (Meehl et al., 2007). Weighted linear combinations of the clear-air turbulence diagnostics calculated from numerical weather prediction models have been found to have significant skill when verified against pilot reports (PIREPs), and these combinations are currently being used for operational turbulence predictions (Sharman et al., 2006).

Probability distributions for the ensemble of 21 clear-air turbulence diagnostics are shown as histograms in Fig. 1. The diagnostics are calculated from daily mean temperature and wind fields over 20 winters in each simulation. The diagnostics are described in detail by Sharman et al. (2006). They include the Colson and Panofsky (1965) index, the Brown (1973) index, and the Ellrod and Knapp (1992) indices. For each diagnostic, greater values are associated with stronger turbulence, where greater here means closer to plus infinity rather than simply greater in magnitude. When the atmo- spheric $\mathrm{CO}_{2}$ concentration is doubled from its pre-industrial value of $280 \mathrm{ppm}$ to $560 \mathrm{ppm}$, probability generally shifts to the right in the histograms of Fig. 1, causing the diagnostics to gain probability in their right-hand tails. These shifts imply a reduction in the prevalence of smooth air and an increase in the prevalence of turbulent air. Exceptionally, the Brown index and the magnitude of the potential vorticity gain probability in their left-hand tails as well as their right-hand tails. Aviation-affecting turbulence lies far into the right-hand tails, which are the parts of the probability distributions that we wish to analyse in detail.

To proceed, it is advantageous to convert the 21 clearair turbulence diagnostics into eddy dissipation rates. The eddy dissipation rate is a natural measure for quantifying the strength of turbulence. For a given aircraft type, aircraft weight, airspeed, and altitude, the rootmean-square vertical acceleration of the aircraft in turbulence is proportional to the cube-root of the eddy dissipation rate (MacCready, 1964). For a large commercial aircraft, cube-rooted eddy dissipation rates of $0.0-0.1 \mathrm{~m}^{2 / 3} \mathrm{~s}^{-1}$ generate null turbulence, $0.1-0.2 \mathrm{~m}^{2 / 3} \mathrm{~s}^{-1}$ generate light turbulence, $0.2-0.3 \mathrm{~m}^{2 / 3} \mathrm{~s}^{-1}$ generate lightto-moderate turbulence, $0.3-0.4 \mathrm{~m}^{2 / 3} \mathrm{~s}^{-1}$ generate moderate turbulence, $0.4-0.5 \mathrm{~m}^{2 / 3} \mathrm{~s}^{-1}$ generate moderate-to-severe turbulence, $0.5-0.6 \mathrm{~m}^{2 / 3} \mathrm{~s}^{-1}$ generate severe turbulence, $0.6-0.7 \mathrm{~m}^{2 / 3} \mathrm{~s}^{-1}$ generate severe-to-extreme turbulence, and values greater than $0.7 \mathrm{~m}^{2 / 3} \mathrm{~s}^{-1}$ generate extreme turbulence (Lane et al., 2012; Williams, 2014; Sharman et al., 2014).

According to atmospheric measurements and models, the eddy dissipation rate and its cube root are log-normally distributed (Frehlich and Sharman, 2004). The log-normal distribution has two degrees of freedom, because it is completely specified by the mean and standard deviation of the underlying normal distribution. Any two independent constraints on the cumulative distribution function of the log-normal distribution will uniquely define the values of these two parameters. Here, we require that the probability of light-or-greater turbulence (with a cube-rooted eddy dissipation rate greater than $0.1 \mathrm{~m}^{2 / 3} \mathrm{~s}^{-1}$ ) is $3.0 \%$ (Watkins and Browning, 1973; Kim and Chun, 2016) and that the probability of moderate-orgreater turbulence (with a cube-rooted eddy dissipation rate greater than $0.3 \mathrm{~m}^{2 / 3} \mathrm{~s}^{-1}$ ) is $0.4 \%$ (Sharman et al., 2006; Kim and Chun, 2016). This definition of moderate-or-greater turbulence is slightly different from the one used by Williams and Joshi (2013). These two constraints on the cumulative distribution function allow us to infer that the natural logarithm of the cube-rooted eddy dissipation rate (divided by $1 \mathrm{~m}^{2 / 3} \mathrm{~s}^{-1}$ to produce a dimensionless numerical value) is normally distributed with a mean and standard deviation of -5.00 and 1.43 , respectively. These values agree with the results of other studies (e.g., Sharman et al., 2014; Sharman and Pearson, 2017) to within a factor of about two, with any discrepancies presumably attributable to the different empirical input data used to constrain the estimates.

The above log-normal distribution for the cube-rooted eddy dissipation rate yields percentile ranges for each turbulence strength category. These percentile ranges and their 

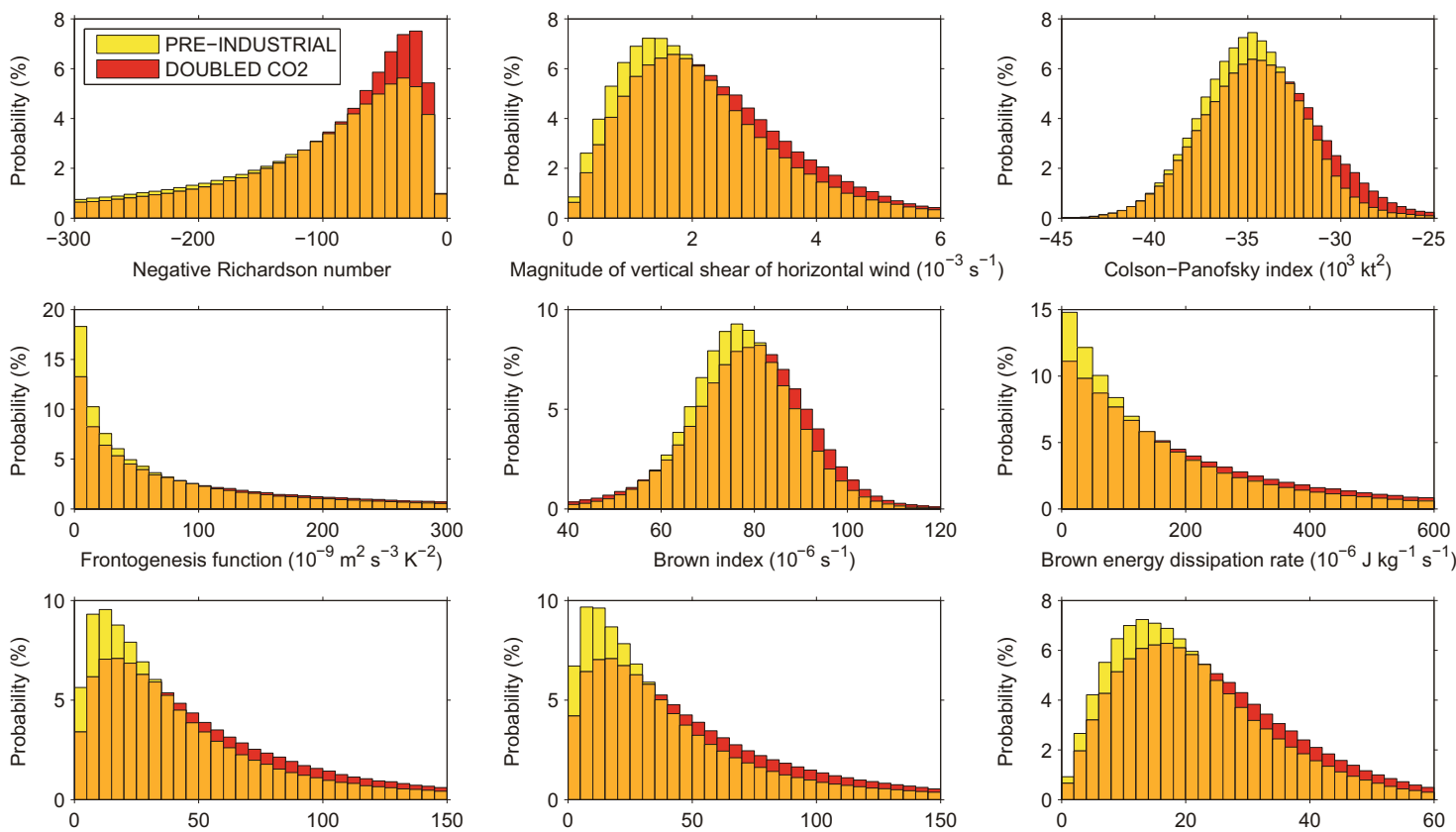

Variant 1 of Ellrod's turbulence index $\left(10^{-9} \mathrm{~s}^{-2}\right)$
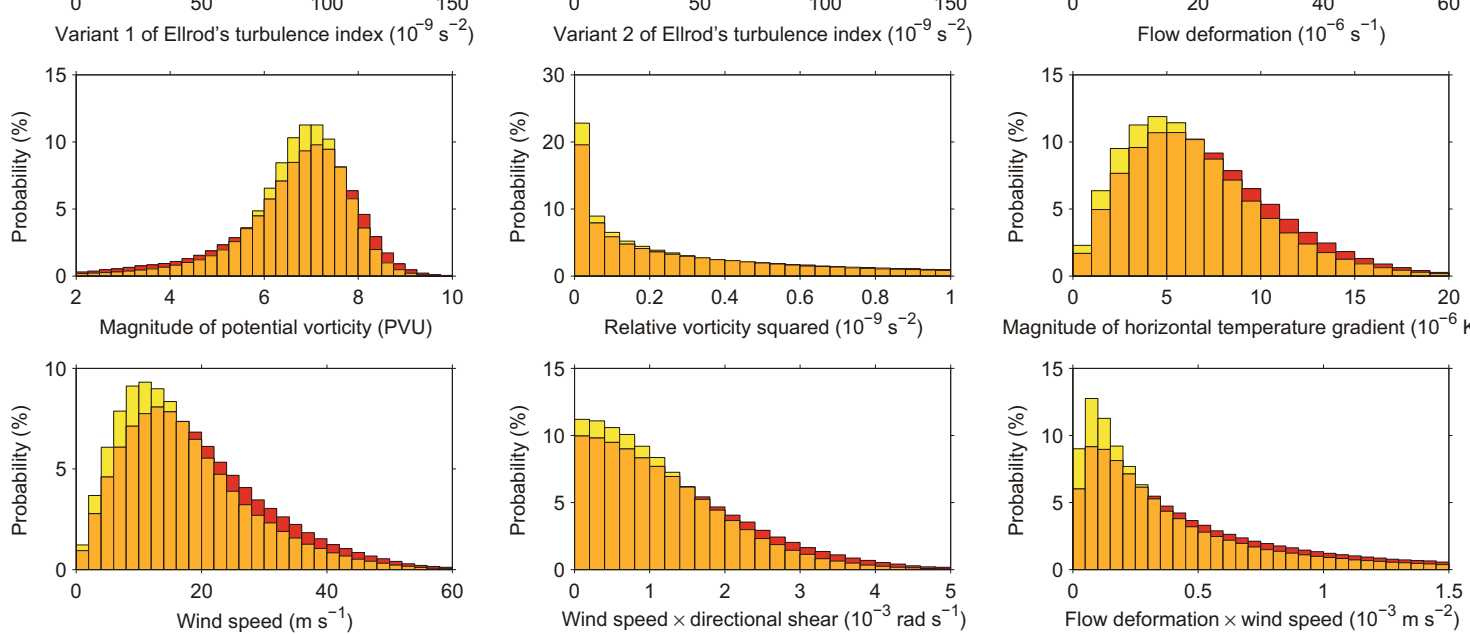

Magnitude of horizontal temperature gradient $\left(10^{-6} \mathrm{~K} \mathrm{~m}^{-1}\right)$
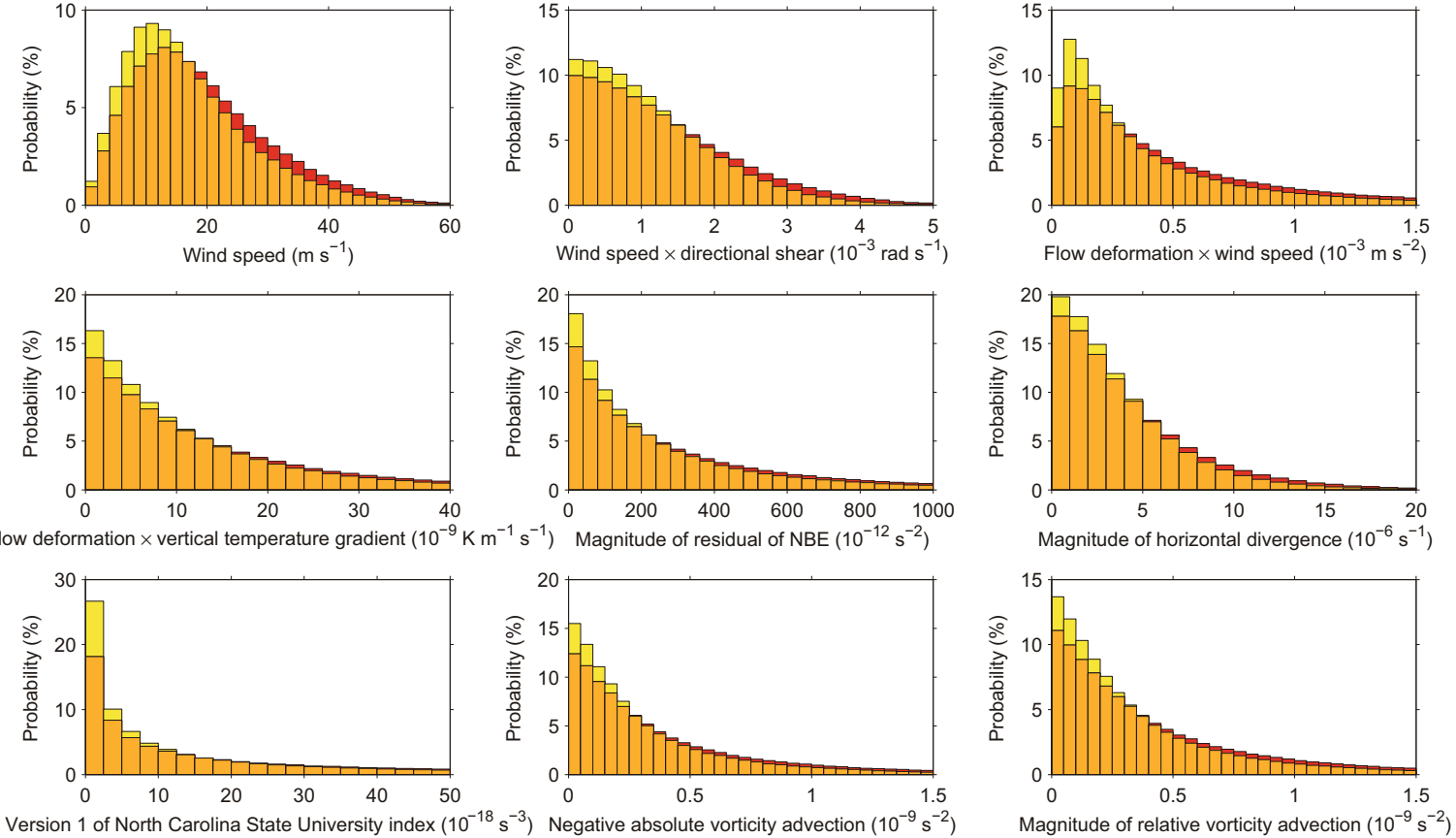

Fig. 1. Probability distributions for 21 clear-air turbulence diagnostics within the North Atlantic flight corridor at $200 \mathrm{hPa}$ in winter. The distributions are calculated from a pre-industrial control simulation and a doubled- $\mathrm{CO}_{2}$ simulation, as described in the text. The histograms show the probability $(\%)$ for turbulence to occur within each finite-width bin. NBE is the nonlinear balance equation. In the units, $\mathrm{kt}$ is knots and $1 \mathrm{PVU}$ is $10^{-6} \mathrm{~m}^{2} \mathrm{~s}^{-1} \mathrm{~K} \mathrm{~kg}^{-1}$.

corresponding probabilities are listed in Table 1. Severe-toextreme and extreme turbulence are neglected because of their rarity. Note that, by construction, the probability of light-or-greater turbulence is $3.0 \%$ and the probability of moderate-or-greater turbulence is $0.4 \%$. The probabilities for each turbulence strength category agree reasonably well 
with the relative frequencies at which the categories appear in automated in-flight measurements (Williams, 2014) and in PIREPs in the United States (Schwartz, 1996) and South Korea (Kim and Chun, 2011). Exact quantitative agreement cannot be expected, because of inconsistent PIREP reporting practices and because automated measurements and PIREPs contain a substantial avoidance bias, which is caused by pilots attempting to evade the strongest turbulence (Sharman et al., 2014).

We may now apply the percentile ranges listed in Table 1 to the pre-industrial probability distributions shown in Fig. 1. By doing so, we may infer the onset threshold for each strength category and each turbulence diagnostic. For $N$ data points, we compute the value of a given percentile using the method of linear interpolation between closest ranks, as follows. First, the $N$ data points are sorted into ascending order and taken to be the values of the $(100 \times 0.5 / N)$ th, $(100 \times$ $1.5 / N)$ th, $\ldots,[100 \times(N-0.5) / N]$ th percentiles. Then, linear interpolation is used to compute the value of any given per- centile between the $(100 \times 0.5 / N)$ th and $[100 \times(N-0.5) / N]$ th percentiles.

In our case, there are $22 \times 14=308$ model gridpoints in the geographic area being studied, and there are $20 \times$ $(31+31+28)=1800$ days in 20 winters (from 1 December to 28 February inclusive). Therefore, we have a total of $N=308 \times 1800=554400$ data points in each of the probability distributions shown in Fig. 1. It follows that each of the pre-industrial probability distributions contains approximately 12000 light turbulence data points, 2800 lightto-moderate data points, 1100 moderate data points, 550 moderate-to-severe data points, and 550 severe data points. Therefore, each turbulence strength category is well sampled. The onset thresholds calculated in the above manner are listed in Table 2. Note that the thresholds are dependent on the grid resolution of the atmospheric model. Therefore, the values listed in Table 2 may differ from those computed in other studies (e.g., Sharman et al., 2006). For example, the Colson-Panofsky thresholds in Table 2 are negative, be-

Table 1. The defining characteristics of six turbulence strength categories for a large commercial aircraft. EDR is the eddy dissipation rate and $g$ is the acceleration due to gravity. The vertical acceleration assumes proportionality to $\mathrm{EDR}^{1 / 3}$, subject to the onset of severe turbulence occurring at $1.0 \mathrm{~g}$. The percentile ranges and probabilities are calculated using an assumed log-normal probability distribution, as described in the text.

\begin{tabular}{lcccccc}
\hline Turbulence strength category & Null & Light & Light-to-moderate & Moderate & Moderate-to-severe & Severe \\
\hline EDR $^{1 / 3}$ range $\left(\mathrm{m}^{2 / 3} \mathrm{~s}^{-1}\right)$ & $0-0.1$ & $0.1-0.2$ & $0.2-0.3$ & $0.3-0.4$ & $0.4-0.5$ & $>0.5$ \\
Vertical acceleration range $(g)$ & $0-0.2$ & $0.2-0.4$ & $0.4-0.6$ & $0.6-0.8$ & $0.8-1.0$ & $>1.0$ \\
Percentile range (\%) & $0-97.0$ & $97.0-99.1$ & $99.1-99.6$ & $99.6-99.8$ & $99.8-99.9$ & $99.9-100$ \\
Probability (\%) & 97.0 & 2.1 & 0.5 & 0.2 & 0.1 & 0.1 \\
\hline
\end{tabular}

Table 2. Onset thresholds for each turbulence strength category and each clear-air turbulence diagnostic. The thresholds are calculated by applying the percentile ranges listed in Table 1 to the pre-industrial probability distributions shown in Fig. 1, as described in the text. The thresholds are for turbulence diagnosed from the GFDL-CM2.1 climate model and apply to large commercial aircraft. In the units column, $\mathrm{kt}$ is knots and $1 \mathrm{PVU}$ is $10^{-6} \mathrm{~m}^{2} \mathrm{~s}^{-1} \mathrm{~K} \mathrm{~kg}^{-1}$.

\begin{tabular}{|c|c|c|c|c|c|c|}
\hline Diagnostic & Units & Light & $\begin{array}{l}\text { Light-to- } \\
\text { moderate }\end{array}$ & Moderate & $\begin{array}{l}\text { Moderate-to- } \\
\text { severe }\end{array}$ & Severe \\
\hline Negative Richardson number & - & -15.4 & -9.8 & -7.9 & -6.7 & -5.9 \\
\hline Magnitude of vertical shear of horizontal wind & $10^{-3} \mathrm{~s}^{-1}$ & 5.3 & 6.6 & 7.4 & 7.9 & 8.4 \\
\hline Colson-Panofsky index & $10^{3} \mathrm{kt}^{2}$ & -29.3 & -27.0 & -25.2 & -23.7 & -22.2 \\
\hline Frontogenesis function & $10^{-9} \mathrm{~m}^{2} \mathrm{~s}^{-3} \mathrm{~K}^{-2}$ & 770 & 1280 & 1660 & 1980 & 2340 \\
\hline Brown index & $10^{-6} \mathrm{~s}^{-1}$ & 99 & 106 & 110 & 113 & 118 \\
\hline Brown energy dissipation rate & $10^{-6} \mathrm{~J} \mathrm{~kg}^{-1} \mathrm{~s}^{-1}$ & 870 & 1370 & 1730 & 2030 & 2330 \\
\hline Variant 1 of Ellrod's turbulence index & $10^{-9} \mathrm{~s}^{-2}$ & 195 & 292 & 360 & 419 & 472 \\
\hline Variant 2 of Ellrod's turbulence index & $10^{-9} \mathrm{~s}^{-2}$ & 184 & 282 & 356 & 419 & 477 \\
\hline Flow deformation & $10^{-6} \mathrm{~s}^{-1}$ & 50.9 & 60.9 & 66.9 & 71.8 & 76.3 \\
\hline Magnitude of potential vorticity & PVU & 8.33 & 8.73 & 8.98 & 9.19 & 9.41 \\
\hline Relative vorticity squared & $10^{-9} \mathrm{~s}^{-2}$ & 2.46 & 3.74 & 4.70 & 5.50 & 6.24 \\
\hline Magnitude of horizontal temperature gradient & $10^{-6} \mathrm{~K} \mathrm{~m}^{-1}$ & 14.7 & 17.6 & 19.4 & 20.8 & 22.0 \\
\hline Wind speed & $\mathrm{m} \mathrm{s}^{-1}$ & 40.9 & 48.4 & 52.4 & 55.3 & 58.5 \\
\hline Wind speed $\times$ directional shear & $10^{-3} \mathrm{rad} \mathrm{s}^{-1}$ & 3.21 & 3.94 & 4.39 & 4.72 & 5.08 \\
\hline Flow deformation $\times$ wind speed & $10^{-3} \mathrm{~m} \mathrm{~s}^{-2}$ & 1.65 & 2.29 & 2.76 & 3.17 & 3.54 \\
\hline Flow deformation $\times$ vertical temperature gradient & $10^{-9} \mathrm{~K} \mathrm{~m}^{-1} \mathrm{~s}^{-1}$ & 53 & 84 & 106 & 127 & 151 \\
\hline Magnitude of residual of nonlinear balance equation & $10^{-12} \mathrm{~s}^{-2}$ & 1230 & 1840 & 2270 & 2610 & 2960 \\
\hline Magnitude of horizontal divergence & $10^{-6} \mathrm{~s}^{-1}$ & 11.9 & 15.7 & 18.2 & 20.4 & 22.5 \\
\hline Version 1 of North Carolina State University index & $10^{-18} \mathrm{~s}^{-3}$ & 1200 & 3600 & 6300 & 9300 & 13000 \\
\hline Negative absolute vorticity advection & $10^{-9} \mathrm{~s}^{-2}$ & 1.33 & 1.86 & 2.23 & 2.56 & 2.93 \\
\hline Magnitude of relative vorticity advection & $10^{-9} \mathrm{~s}^{-2}$ & 1.44 & 1.99 & 2.34 & 2.66 & 3.00 \\
\hline
\end{tabular}


cause the Colson-Panofsky index is proportional to $1-\mathrm{Ri} / 0.5$, and the Richardson number ( $\mathrm{Ri}$ ) is rarely less than 0.5 in the GFDL-CM2.1 model.

The onset thresholds listed in Table 2 facilitate a detailed examination of the right-hand tails of the probability distributions shown in Fig. 1. Close-ups of the right-hand tails are shown in Fig. 2. As anticipated, the probability distributions for the ensemble of 21 clear-air turbulence diagnostics gen-
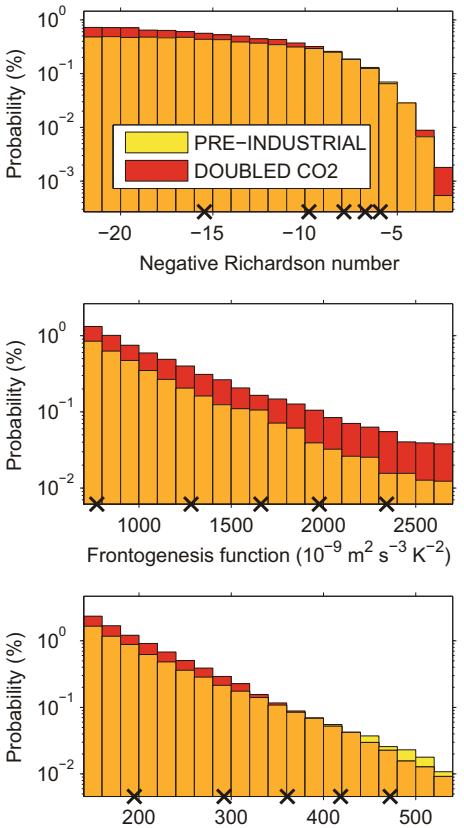

Variant 1 of Ellrod's turbulence index $\left(10^{-9} \mathrm{~s}^{-2}\right)$
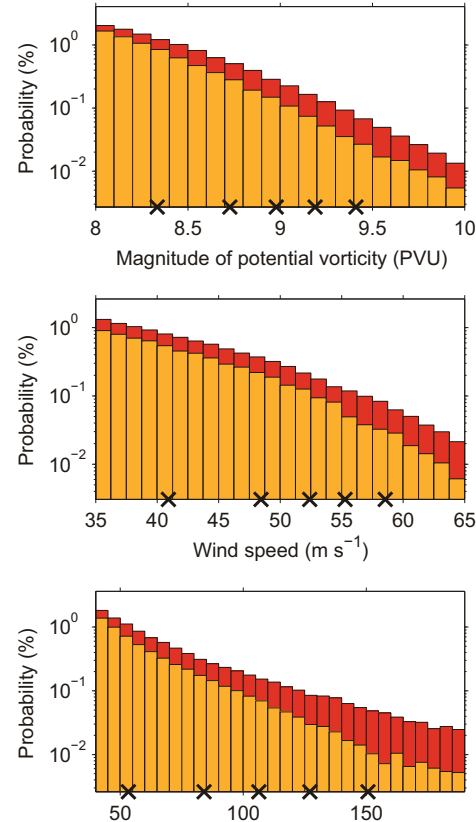

Flow deformation $\times$ vertical temperature gradient $\left(10^{-9} \mathrm{~K}\right.$

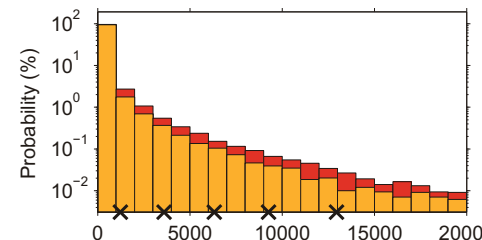

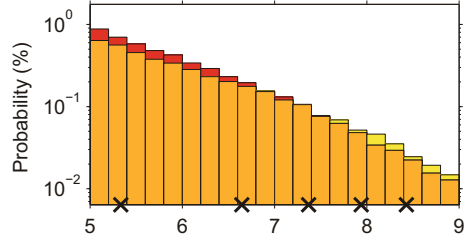

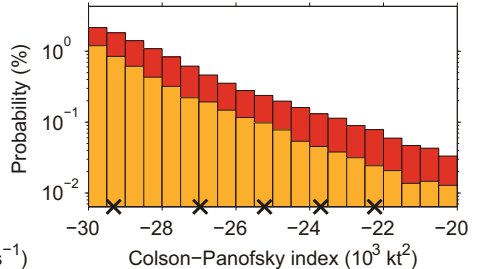

Magnitude of vertical shear of horizontal wind $\left(10^{-3} \mathrm{~s}^{-1}\right)$
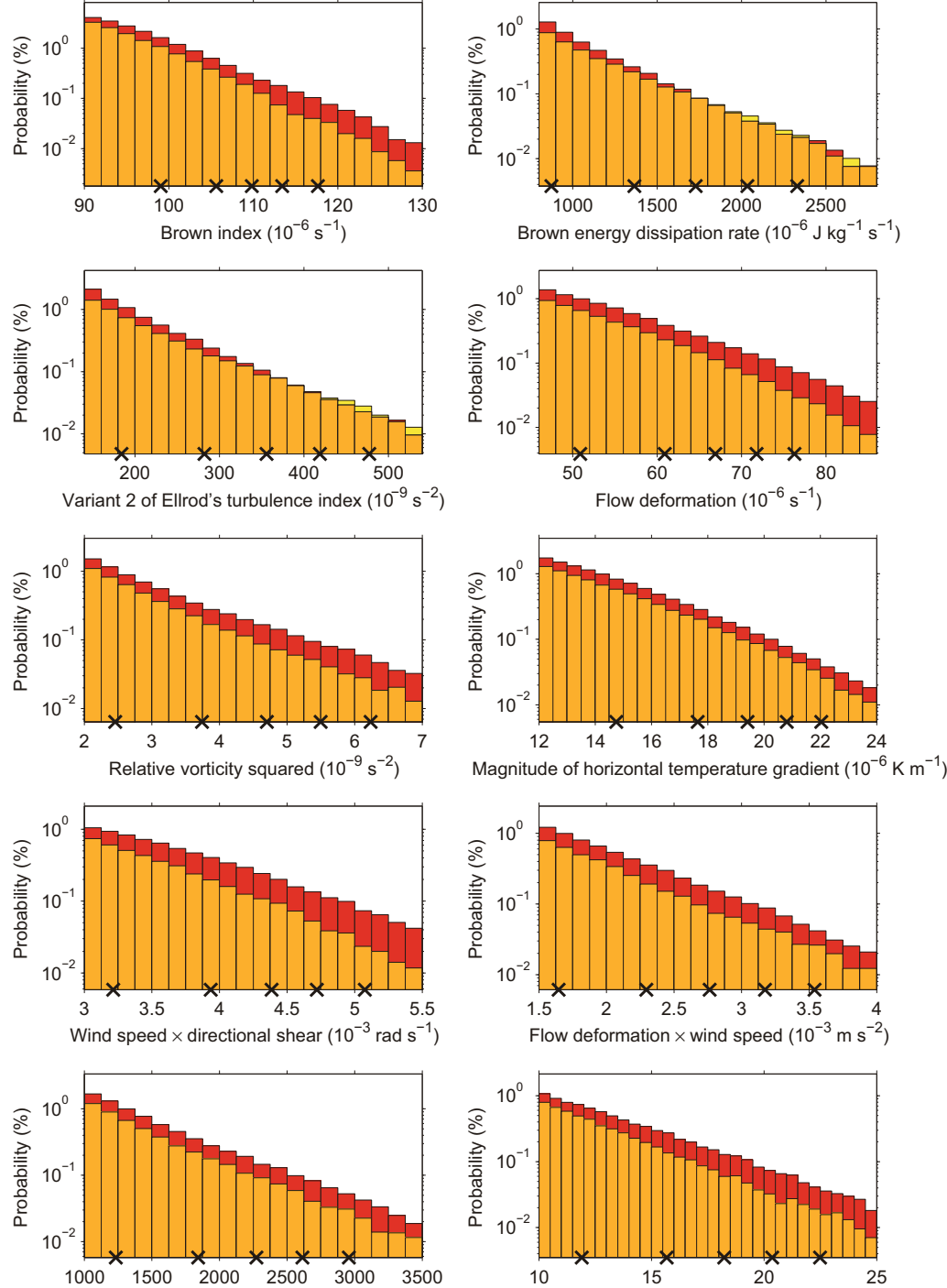

Magnitude of horizontal divergence $\left(10^{-6} \mathrm{~s}^{-1}\right)$
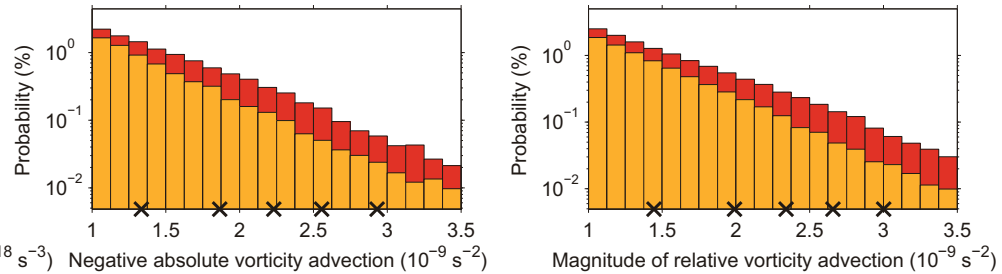

Fig. 2. Same as Fig. 1, but showing enlarged views of the right-hand tails of the probability distributions. The probability axes are logarithmic. On each turbulence diagnostic axis, the five markers indicate the onset thresholds for light, light-to-moderate, moderate, moderate-to-severe, and severe turbulence, as listed in Table 2. 
erally gain probability in their right-hand tails when the $\mathrm{CO}_{2}$ is doubled. The onset thresholds for each turbulence strength category are indicated by markers on the turbulence diagnostic axes in Fig. 2. Reference to the markers indicates that the increase in probability occurs in nearly all of the diagnostics and nearly all of the strength categories. The increased probabilities represent increases in the volume of airspace containing turbulence.

The probability distributions shown in Fig. 2 may be integrated between each pair of adjacent markers, enabling the probability gains to be calculated per strength category and per turbulence diagnostic. These gains, expressed as percentage increases in the doubled- $\mathrm{CO}_{2}$ climate relative to the pre-industrial climate, are shown in Fig. 3. Most of the 21 diagnostics show increased turbulence in all five strength categories. Specifically, all 21 diagnostics show increases in the amount of light and light-to-moderate turbulence, and at least 16 of the 21 diagnostics show increases in the amount of moderate, moderate-to-severe, and severe turbulence. To summarise the 21 different estimates of the percentage increase within each strength category, we calculate the median (50th percentile) and 25th-75th percentiles, which respectively indicate an ensemble-average value and an intra-ensemble range. By these measures, the prevalence of light turbulence increases by 59\% (43\%-68\%), light-tomoderate by $75 \%(39 \%-96 \%)$, moderate by $94 \%(37 \%-$ $118 \%$ ), moderate-to-severe by $127 \%(30 \%-170 \%)$, and severe by $149 \%(36 \%-188 \%)$. The averages and ranges both increase substantially from light to severe turbulence, suggesting greater percentage increases in stronger turbulence than weaker turbulence, but also implying a higher degree of uncertainty.

A geographic map of the spatial distribution of the changing prevalence of light-or-greater clear-air turbulence in the North Atlantic region is shown in Fig. 4. Similar maps for moderate-or-greater and severe-or-greater clear-air turbulence are shown in Fig. 5 and Fig. 6, respectively. Within the regions delineated by the black dashed lines in these figures, the agreement between the 21 diagnostics on the sign of the change is statistically significant at the $90 \%$ level. The significance here is assessed using the binomial distribution, under the null hypothesis that each of the 21 diagnostics is independent and equally likely to increase or decrease, following Williams and Joshi (2013). Within most of the North Atlantic region, a statistically significant majority of the diagnostics agree on an increased frequency of light-or-greater turbulence. For moderate-or-greater turbulence, the area of significant agreement is reduced, but it still occupies most of the North Atlantic region north of $50^{\circ} \mathrm{N}$. For severe-orgreater turbulence, the area of significant agreement is further reduced, but it still occupies most of the region between Canada, Greenland, and the UK, which is a very busy part of the North Atlantic flight corridor.

\section{Summary and discussion}

This paper has used climate model simulations to analyse the transatlantic wintertime clear-air turbulence response to climate change in five aviation-relevant turbulence strength categories. We have found that the probability distributions

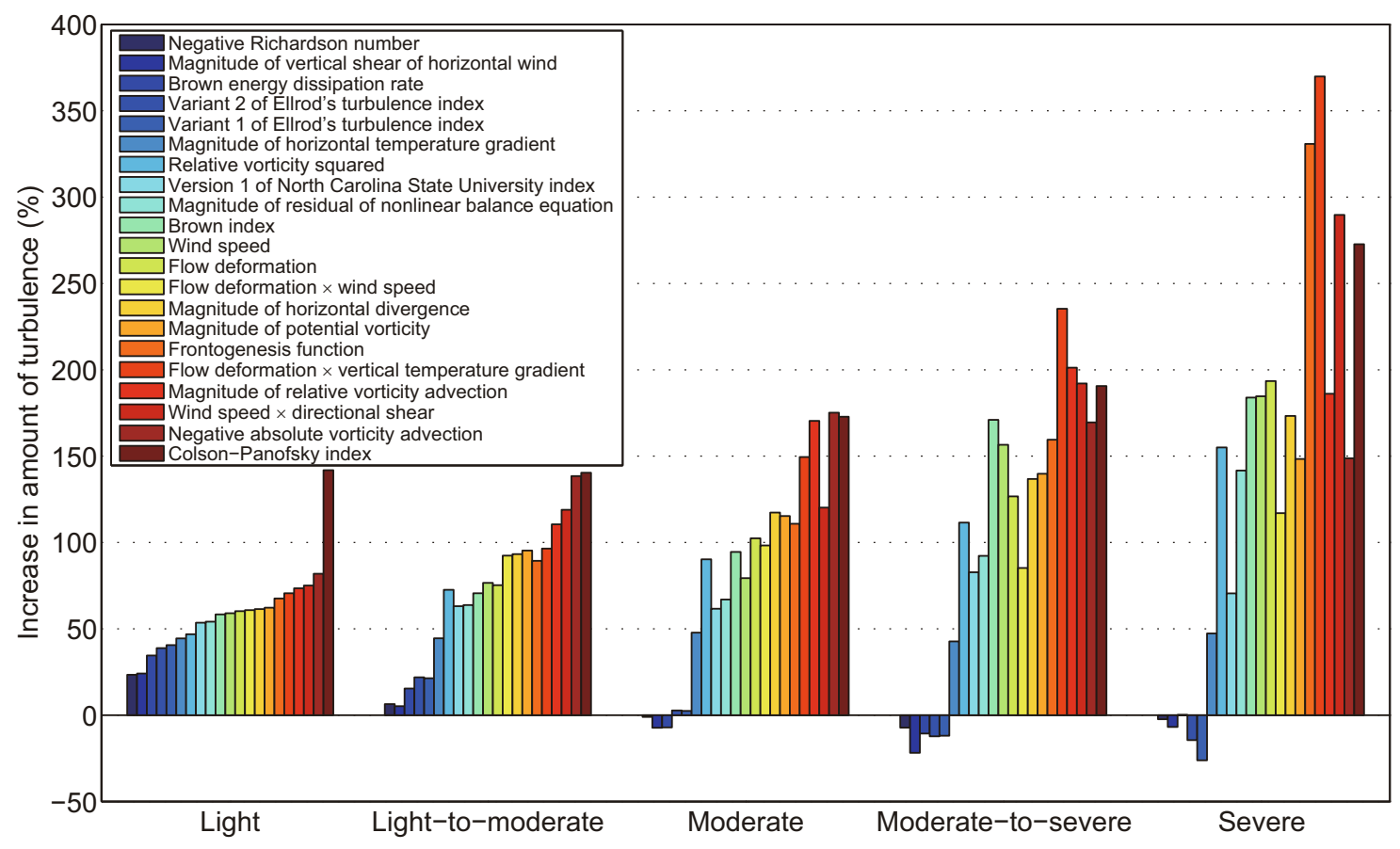

Fig. 3. Bar charts showing the percentage increase in the amount of light, light-to-moderate, moderate, moderate-tosevere, and severe clear-air turbulence within the North Atlantic flight corridor at $200 \mathrm{hPa}$ in winter. The increase refers to the change in a doubled- $\mathrm{CO}_{2}$ simulation compared to a pre-industrial simulation. The 21 clear-air turbulence diagnostics are ordered within each strength category according to the magnitude of the change in the light category. 


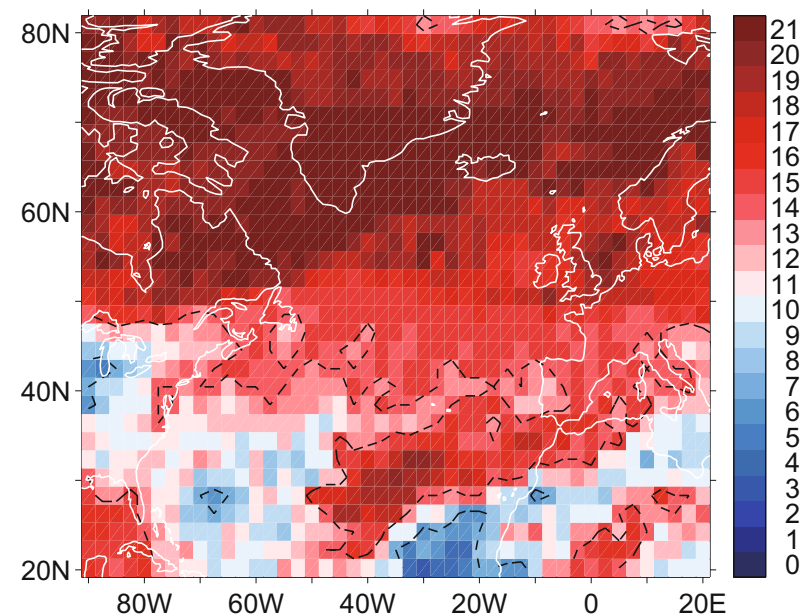

Fig. 4. Spatial distribution of the number of the 21 clear-air turbulence diagnostics to show an increase in the frequency of light-or-greater clear-air turbulence at $200 \mathrm{hPa}$ in winter. The increase refers to the change in a doubled- $\mathrm{CO}_{2}$ simulation compared to a pre-industrial simulation. Red shading indicates that most of the diagnostics show an increase, and blue shading indicates that most show a decrease. The black dashed lines, which are contours at 7 and 14, delineate the regions in which at least two-thirds of the diagnostics agree on the sign of the change.

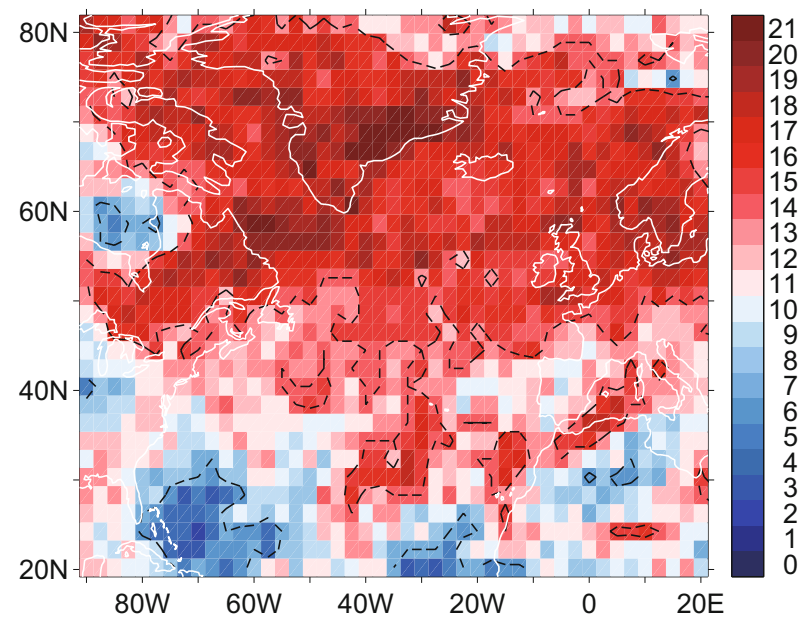

Fig. 5. Same as Fig. 4, but for moderate-or-greater turbulence.

for an ensemble of 21 clear-air turbulence diagnostics generally gain probability in their right-hand tails when the atmospheric $\mathrm{CO}_{2}$ concentration is doubled. By converting the diagnostics into eddy dissipation rates, we have found substantial increases in the airspace volume containing light, light-tomoderate, moderate, moderate-to-severe, and severe clear-air turbulence. We conclude that the amount of transatlantic wintertime clear-air turbulence in the atmosphere will increase significantly in all aviation-relevant strength categories as the climate changes.

The projected increases in the prevalence of clear-air turbulence do not necessarily imply more in-flight injuries or greater levels of passenger discomfort. Aircraft bumpiness

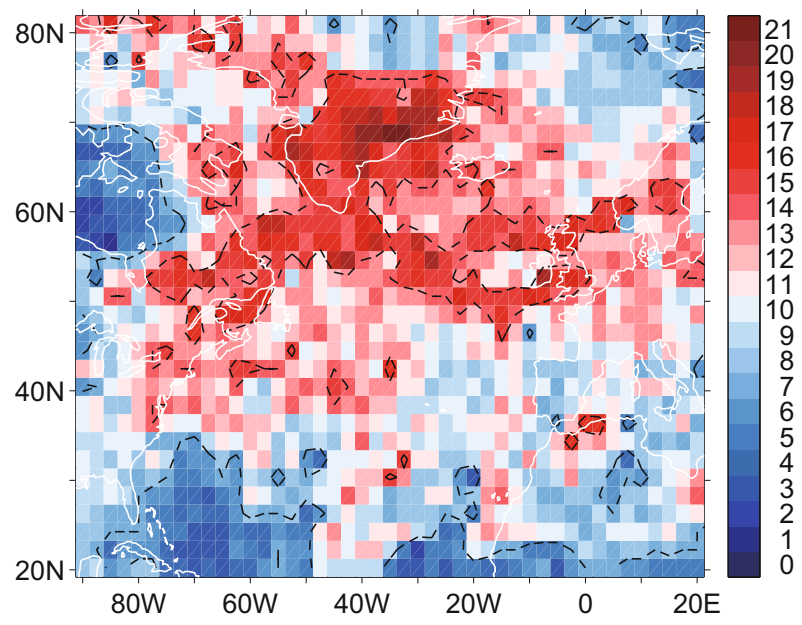

Fig. 6. Same as Fig. 4, but for severe-or-greater turbulence.

depends on a number of other factors in addition to the strength and frequency of atmospheric turbulence. One factor is the skill of operational clear-air turbulence forecasts, such as the Graphical Turbulence Guidance system (Sharman et al., 2006). Any future improvements in these forecasting algorithms would improve the ability of pilots to divert around patches of clear-air turbulence instead of unexpectedly encountering them. Another factor is the dynamical response of aircraft to turbulence. Some modern aircraft are fitted with an accelerometer in their nose cone. If the accelerometer registers a sudden change in altitude, which is large enough to be indicative of turbulence, then the wing flaps are rapidly adjusted in an attempt to damp the vertical motion and reduce the acceleration. It is only in the absence of these changing extraneous factors that the quantitative turbulence increases calculated herein would be expected to translate proportionately into stronger and more frequent turbulence encounters by aircraft.

Another potentially relevant factor is the development of on-board technology to detect clear-air turbulence. In principle, the increased risk of clear-air turbulence encounters in future could be mitigated by equipping aircraft with Light Detection and Ranging (LIDAR) ultra-violet laser systems (Vrancken et al., 2016). Forward-looking LIDAR could forewarn pilots of any invisible density perturbations indicative of clear-air turbulence up to $10-15 \mathrm{~km}$ ahead, potentially with enough lead time to alert passengers and crew or even to attempt an evasive manoeuvre. Kauffmann (2002) has calculated that the business case for installing LIDAR technology is currently negative. In other words, the economic costs of retro-fitting aircraft currently exceed the economic benefits of avoiding clear-air turbulence. However, it is likely that the business case will improve in future, as the LIDAR technology becomes less expensive and clear-air turbulence becomes more prevalent.

In addition to the impacts on aviation, any increase in clear-air turbulence could also have important consequences for atmospheric dynamics and thermodynamics. Clear-air turbulence mixes atmospheric constituents in the stratosphere 
(Lilly et al., 1974) and across the tropopause (Shapiro, 1980; Traub and Lelieveld, 2003; Karpechko et al., 2007). Therefore, any increase in clear-air turbulence would increase the troposphere-stratosphere exchange of radiatively significant constituents such as ozone and water vapour. This increased exchange could modify the temperature structure of the tropopause region (Forster and Shine, 2002), which could have dynamical consequences throughout the troposphere (Maycock et al., 2013). These possible impacts of increased clear-air turbulence on the large-scale atmospheric circulation have not yet been explored but should be a priority for future research.

Future work should extend our study by examining other seasons, flight levels, and geographic regions. The sensitivity of our results to the climate model resolution should also be explored. It would be informative to compare turbulence diagnosed from climate models with in-flight turbulence measurements and also with turbulence diagnosed from reanalysis data. These comparisons are likely to require interdisciplinary collaborations between climate scientists, turbulence scientists, and airlines. Scientific and socioeconomic uncertainties should be quantified by using different climate models and greenhouse-gas scenarios, respectively. Another source of uncertainty is that future lower-stratospheric temperature changes, which influence the meridional temperature gradient at aircraft cruising altitudes in the midlatitudes, depend on warming from ozone recovery in addition to cooling from greenhouse gases (Shine et al., 2003). Convection may interact with clear-air turbulence (Trier et al., 2012; Trier and Sharman, 2016) and the response of this interaction to climate change should be investigated. Finally, future studies should investigate the response of severe-to-extreme and extreme clear-air turbulence to climate change. Turbulence in these strength categories is so rare that very long climate model simulations will be required in order to generate robust statistics, presenting a technical challenge that will need to be overcome.

Acknowledgements. The author is financially supported through a University Research Fellowship from the Royal Society (reference UF130571). He thanks Jenny LIN for her invitation and encouragement to write an article on aviation turbulence. The author acknowledges the modelling groups, the Program for Climate Model Diagnosis and Intercomparison, and the World Climate Research Programme's Working Group on Coupled Modelling for their roles in making available the climate model data. Support of this dataset is provided by the Office of Science, US Department of Energy. The constructive comments of four reviewers are gratefully acknowledged.

Open Access. This article is distributed under the terms of the Creative Commons Attribution 4.0 International License (http://creativecommons.org/licenses/by/4.0/), which permits unrestricted use, distribution, and reproduction in any medium, provided you give appropriate credit to the original author(s) and the source, provide a link to the Creative Commons license, and indicate if changes were made.

\section{REFERENCES}

Atlas, D., J. I. Metcalf, J. H. Richter, and E. E. Gossard, 1970: The birth of "CAT" and microscale turbulence. J. Atmos. Sci., 27, 903-913.

Brown, R., 1973: New indices to locate clear-air turbulence. Meteor. Mag., 102, 347-361.

Burbidge, R., 2016: Adapting European airports to a changing climate. Transportation Research Procedia, 14, 14-23.

Clark, T. L., W. D. Hall, R. M. Kerr, D. Middleton, L. Radke, F. M. Ralph, P. J. Neiman, and D. Levinson, 2000: Origins of aircraft-damaging clear-air turbulence during the 9 December 1992 Colorado downslope windstorm: Numerical simulations and comparison with observations. J. Atmos. Sci., 57, 1105 1131.

Coffel, E., and R. Horton, 2015: Climate change and the impact of extreme temperatures on aviation. Weather, Climate, and Society, 7, 94-102.

Colson, D., and H. A. Panofsky, 1965: An index of clear air turbulence. Quart. J. Roy. Meteor. Soc., 91, 507-513.

Delcambre, S. C., D. J. Lorenz, D. J. Vimont, and J. E. Martin, 2013: Diagnosing northern hemisphere jet portrayal in 17 CMIP3 global climate models: Twenty-first-century projections. J. Climate, 26, 4930-4946.

Ellrod, G. P., and D. I. Knapp, 1992: An objective clear-air turbulence forecasting technique: Verification and operational use. Wea. Forecasting, 7, 150-165.

Endlich, R. M., 1964: The mesoscale structure of some regions of clear-air turbulence. J. Atmos. Sci., 3, 261-276.

FAA, 2006: Preventing injuries caused by turbulence. Advisory Circular 120-88A, Federal Aviation Administration, Washington, DC.

Forster, P. M. de F., and K. P. Shine, 2002: Assessing the climate impact of trends in stratospheric water vapor. Geophys. Res. Lett., 29, 1086.

Francis, J. A., and S. J. Vavrus, 2012: Evidence linking Arctic amplification to extreme weather in mid-latitudes. Geophys. Res. Lett., 39, L06801.

Frehlich, R., and R. Sharman, 2004: Estimates of turbulence from numerical weather prediction model output with applications to turbulence diagnosis and data assimilation. Mon. Wea. Rev., 132, 2308-2324.

Goessling, H. F., and S. Bathiany, 2016: Why $\mathrm{CO}_{2}$ cools the middle atmosphere-A consolidating model perspective. Earth System Dynamics, 7, 697-715.

ICAO, 2015: International Civil Aviation Organization (ICAO) Second High-Level Safety Conference (HLSC), Montreal, Canada, 2-5 February 2015, Working Paper on Extreme Meteorological Conditions (HLSC/15-WP/36). [Available online from www.icao.int/ Meetings/HLSC2015/Documents/WP/wp036_en.pdf].

Irvine, E. A., B. J. Hoskins, K. P. Shine, R. W. Lunnon, and C. Froemming, 2013: Characterizing North Atlantic weather patterns for climate-optimal aircraft routing. Meteorological Applications, 20, 80-93.

Irvine, E. A., K. P. Shine, and M. A. Stringer, 2016: What are the implications of climate change for trans-Atlantic aircraft routing and flight time? Transportation Research Part D: Transport and Environment, 47, 44-53.

Jaeger, E. B., and M. Sprenger, 2007: A Northern Hemispheric climatology of indices for clear air turbulence in the tropopause region derived from ERA40 reanalysis data. J. Geophys. Res., 
112(D20), D20106.

Karnauskas, K. B., J. P. Donnelly, H. C. Barkley, and J. E. Martin, 2015: Coupling between air travel and climate. Nature Clim. Change, 5, 1068-1073.

Karpechko, A., A. Lukyanov, E. Kyrö, S. Khaikin, L. Korshunov, R. Kivi, and H. Vömel, 2007: The water vapour distribution in the Arctic lowermost stratosphere during the LAUTLOS campaign and related transport processes including stratosphere-troposphere exchange. Atmos. Chem. Phys., 7, 107-119.

Kauffmann, P., 2002: The business case for turbulence sensing systems in the US air transport sector. Journal of Air Transport Management, 8, 99-107.

Kim, B., and Coauthors, 2005: System for assessing Aviation's Global Emissions (SAGE), Version 1.5, Technical Manual FAA-EE-2005-01, Federal Aviation Administration, Washington, DC.

Kim, J.-H., and H.-Y. Chun, 2011: Statistics and possible sources of aviation turbulence over South Korea. J. Appl. Meteor. Climatol., 50, 311-324.

Kim, J.-H., W. N. Chan, B. Sridhar, R. D. Sharman, P. D. Williams, and M. Strahan, 2016: Impact of the North Atlantic Oscillation on transatlantic flight routes and clear-air turbulence. $J$. Appl. Meteor. Climatol., 55, 763-771.

Kim, S.-H., and H.-Y. Chun, 2016: Aviation turbulence encounters detected from aircraft observations: Spatiotemporal characteristics and application to Korean Aviation Turbulence Guidance. Meteorological Applications, 23, 594-604.

Knox, J. A., D. W. McCann, and P. D. Williams, 2008: Application of the Lighthill-Ford theory of spontaneous imbalance to clear-air turbulence forecasting. J. Atmos. Sci., 65, 32923304.

Krozel, J., V. Klimenko, and R. Sharman, 2011: Analysis of clear-air turbulence avoidance maneuvers. Air Traffic Control Quarterly, 19, 147-168.

Lane, T. P., R. D. Sharman, S. B. Trier, R. G. Fovell, and J. K. Williams, 2012: Recent advances in the understanding of near-cloud turbulence. Bull. Amer. Meteor. Soc., 93, 499-515.

Lee, D. S., D. W. Fahey, P. M. Forster, P. J. Newton, R. C. N. Wit, L. L. Lim, B. Owen, and R. Sausen, 2009: Aviation and global climate change in the 21st century. Atmos. Environ., 43, 3520-3537.

Lee, L., 2013: A climatological study of clear air turbulence over the North Atlantic. Master's thesis, Dept. of Earth Sciences, Uppsala University.

Lilly, D. K., D. E. Waco, and S. I. Adelfang, 1974: Stratospheric mixing estimated from high-altitude turbulence measurements. J. Appl. Meteor., 13, 488-493.

Lorenz, D. J., and E. T. DeWeaver, 2007: Tropopause height and zonal wind response to global warming in the IPCC scenario integrations. J. Geophys. Res., 112, D10119.

MacCready, P. B., 1964: Standardization of gustiness values from aircraft. J. Appl. Meteor., 3, 439-449.

Malwitz, A., and Coauthors, 2005: System for assessing Aviation's Global Emissions (SAGE), Version 1.5, Validation Assessment, Model Assumptions and Uncertainties. Tech. Rep. FAA-AA-EE-2005-03, Federal Aviation Administration, Washington, DC.

Maycock, A. C., M. M. Joshi, K. P. Shine, and A. A. Scaife, 2013: The circulation response to idealized changes in stratospheric water vapor. J. Climate, 26, 545-561.

McCann, D. W., J. A. Knox, and P. D. Williams, 2012: An im- provement in clear-air turbulence forecasting based on spontaneous imbalance theory: The ULTURB algorithm. Meteorological Applications, 19, 71-78.

Meehl, G. A., and Coauthors, 2007: Global climate projections. Climate Change 2007: The Physical Science Basis. Contribution of Working Group I to the Fourth Assessment Report of the Intergovernmental Panel on Climate Change, Solomon et al., Eds., Cambridge University Press, 747-846.

Meneguz, E., H. Wells, and D. Turp, 2016: An automated system to quantify aircraft encounters with convectively induced turbulence over Europe and the Northeast Atlantic. J. Appl. Meteor. Climatol., 55, 1077-1089.

Penner, J. E., D. H. Lister, D. J. Griggs, D. J. Dokken, and M. McFarland, 1999: Intergovernmental Panel on Climate Change (IPCC) special report: Aviation and the global atmosphere. Cambridge University Press, 373 pp.

Puempel, H., and P. D. Williams, 2016: The impacts of climate change on aviation: Scientific challenges and adaptation pathways. ICAO Environmental Report 2016: On Board A Sustainable Future, 205-207.

Reiter, E. R., 1963: Jet-stream Meteorology. University of Chicago Press, 515 pp.

Riddaway, R. W., 1998: Notes and news. Meteorological Applications, 5, 183-188.

Romps, D. M., J. T. Seeley, D. Vollaro, and J. Molinari, 2014: Projected increase in lightning strikes in the United States due to global warming. Science, 346, 851-854.

Schwartz, B., 1996: The quantitative use of PIREPs in developing aviation weather guidance products. Wea. Forecasting, 11, 372-384.

Shapiro, M. A., 1980: Turbulent mixing within tropopause folds as a mechanism for the exchange of chemical constituents between the stratosphere and troposphere. J. Atmos. Sci., 37, 994-1004.

Sharman, R., C. Tebaldi, G. Wiener, and J. Wolff, 2006: An integrated approach to mid- and upper-level turbulence forecasting. Wea. Forecasting, 21, 268-287.

Sharman, R. D., and J. M. Pearson, 2017: Prediction of energy dissipation rates for aviation turbulence. Part I: Forecasting nonconvective turbulence. J. Appl. Meteor. Climatol., 56, $317-$ 337.

Sharman, R. D., S. B. Trier, T. P. Lane, and J. D. Doyle, 2012: Sources and dynamics of turbulence in the upper troposphere and lower stratosphere: A review. Geophys. Res. Lett., 39, L12803.

Sharman, R. D., L. B. Cornman, G. Meymaris, J. Pearson, and T. Farrar, 2014: Description and derived climatologies of automated in situ eddy-dissipation-rate reports of atmospheric turbulence. J. Appl. Meteor. Climatol., 53, 1416-1432.

Shine, K. P., and Coauthors, 2003: A comparison of modelsimulated trends in stratospheric temperatures. Quart. J. Roy. Meteor. Soc., 129, 1565-1588.

Simpson, I. R., 2016: Climate change predicted to lengthen transatlantic travel times. Environ. Res. Lett., 11, 031002.

Solomon, A., and L. M. Polvani, 2016: Highly significant responses to anthropogenic forcings of the midlatitude jet in the Southern Hemisphere. J. Climate, 29, 3463-3470.

Traub, M., and J. Lelieveld, 2003: Cross-tropopause transport over the eastern Mediterranean. J. Geophys. Res., 108, 4712.

Trier, S. B., and R. D. Sharman, 2016: Mechanisms influencing cirrus banding and aviation turbulence near a convectively enhanced upper-level jet stream. Mon. Wea. Rev., 144, 3003- 
3027.

Trier, S. B., R. D. Sharman, and T. P. Lane, 2012: Influences of moist convection on a cold-season outbreak of Clear-Air Turbulence (CAT). Mon. Wea. Rev., 140, 2477-2496.

Vallis, G. K., P. Zurita-Gotor, C. Cairns, and J. Kidston, 2015: Response of the large-scale structure of the atmosphere to global warming. Quart. J. Roy. Meteor. Soc., 141, 1479-1501.

Vrancken, P., and Coauthors, 2016: Flight tests of the DELICAT airborne LIDAR system for remote clear air turbulence detection. EPJ Web of Conferences, 119, 14003.

Warner, M., 2013: Boeing: Current market outlook 2013-2032. Boeing Commercial Airplanes, Seattle, WA.

Watkins, C. D., and K. A. Browning, 1973: The detection of clear air turbulence by radar. Physics in Technology, 4, 28-61.

Wilcox, L. J., K. P. Shine, and B. J. Hoskins, 2012: Radiative forcing due to aviation water vapour emissions. Atmos. Environ., 63, 1-13.

Wilkerson, J. T., M. Z. Jacobson, A. Malwitz, S. Balasubramanian, R. Wayson, G. Fleming, A. D. Naiman, and S. K. Lele, 2010: Analysis of emission data from global commercial aviation: 2004 and 2006. Atmos. Chem. Phys., 10, 6391-6408.

Williams, J. K., 2014: Using random forests to diagnose aviation turbulence. Machine Learning, 95, 51-70.
Williams, P. D., 2016: Transatlantic flight times and climate change. Environ. Res. Lett., 11, 024008.

Williams, P. D., and M. M. Joshi, 2013: Intensification of winter transatlantic aviation turbulence in response to climate change. Nature Clim. Change, 3, 644-648.

Williams, P. D., and M. M. Joshi, 2016: Clear-air turbulence in a changing climate. Aviation Turbulence: Processes, Detection, Prediction, R. Sharman and T. Lane, Eds., Springer International Publishing, 465-480.

Williams, P. D., P. L. Read, and T. W. N. Haine, 2003: Spontaneous generation and impact of inertia-gravity waves in a stratified, two-layer shear flow. Geophys. Res. Lett., 30, 2255.

Williams, P. D., T. W. N. Haine, and P. L. Read, 2005: On the generation mechanisms of short-scale unbalanced modes in rotating two-layer flows with vertical shear. J. Fluid Mech., 528, 1-22.

Williams, P. D., T. W. N. Haine, and P. L. Read, 2008: Inertiagravity waves emitted from balanced flow: Observations, properties, and consequences. J. Atmos. Sci., 65, 3543-3556.

Wolff, J. K., and R. D. Sharman, 2008: Climatology of upper-level turbulence over the contiguous United States. J. Appl. Meteor. Climatol., 47, 2198-2214. 